\title{
LAND COVER FEATURE EXTRACTION FROM CORONA SPY SATELLITE IMAGES DURING THE COLD WAR - 1968
}

\author{
Dimitris Stratoulias ${ }^{a, b, *}$ and M. Erdem Kabadayl ${ }^{c}$ \\ ${ }^{a}$ Informetrics Research Group, Ton Duc Thang University, Ho Chi Minh City, Vietnam, \\ dimitris.stratoulias@tdtu.edu.vn \\ ${ }^{\mathrm{b}}$ Faculty of Applied Sciences, Ton Duc Thang University, Ho Chi Minh City, Vietnam \\ ' Koç University, Rumelifeneri Yolu, Sariyer, 34450, Istanbul, Turkey; mkabadayi@ku.edu.tr
}

\begin{abstract}
For 25 years the Corona reconnaissance satellite mission has been declassified, making available an unprecedented historic archive of very high spatial resolution panchromatic images acquired during the cold war era. During the same time, Bulgaria has observed a decreasing and ageing population and a slow agricultural productivity. In this study, we attempt to map the settlements around the city of Plovdiv, Bulgaria based on textural analysis of a Corona image acquired in 1968. We compare the results with information derived from recent Sentinel-2B and Landsat-8 images. We discuss on the discerning capability of the Corona image in mapping settlements and the potential usability of textural analysis in the context of land use and land cover mapping of historical images. Overall, we present the textural analysis of an image from one of the first satellite missions and report on the potential for feature extraction from such primitive satellite products.
\end{abstract}

Index Terms - Corona, Sentinel-2, Landsat-8, Haralick texture, NDBI, historical GIS

\section{INTRODUCTION}

The first constellation of spy satellites, named Corona, Argon and Lanyard, operated between 1960 and 1972 and delivered a large earth observation archive of more than 860000 images over eastern Europe and Asia. In 1995 these images were declassified [1] as they were not anymore important for national security and became accessible to scientists and the public alike. Since then, Corona imagery has been used primarily for archaeological applications (e.g. [2-9]), land use / land cover studies (e.g. [10]) and terrain analysis (e.g. [11]) as reported by Awange and Kiema [12]. Despite the large time span of the satellite mission (i.e. 12 years), the fine spatial resolution of the imagery and the 25 years of availability since the declassification, there have not been many studies attempting to associate information extracted from Corona images with field data during this historic time; this fact perhaps can be attributed to the lack of historic concurrent ground truth data from this past time and the technical peculiarities of the raw satellite data, the latter imposing challenges in information and feature extraction from the Corona imagery. In this paper we attempt to identify impervious surfaces, mainly settlements, based on a Corona image over Bulgaria from 1968. Our results are visually evaluated based on recent (i.e. 2019) satellite images from the sensors on board Sentinel-2B and Landsat-8; we discuss differences on patterns and the features' characteristics between the 51 years of time difference.

\section{STUDY AREA}

The study area lies in the Plovdiv region, Bulgaria, South East Europe. We concentrate on settlements around the city of Plovdiv (Figure 1). The country has suffered intense depopulation nation-wide starting from 1989, although the rural population was affected as early as 1975 [13]. Simultaneously, an ageing population problem has been observed in the past [14] and future projections are discouraging. The UN Population Division estimates that Bulgaria will lose $23 \%$ of its current population by 2050, which will make it the fastest shrinking in the world [15]. In this context, settlement development and surrounding agricultural activity in this area are unique in the sense that they have largely remained stable for a very long period, even going back to the 19th century [16].

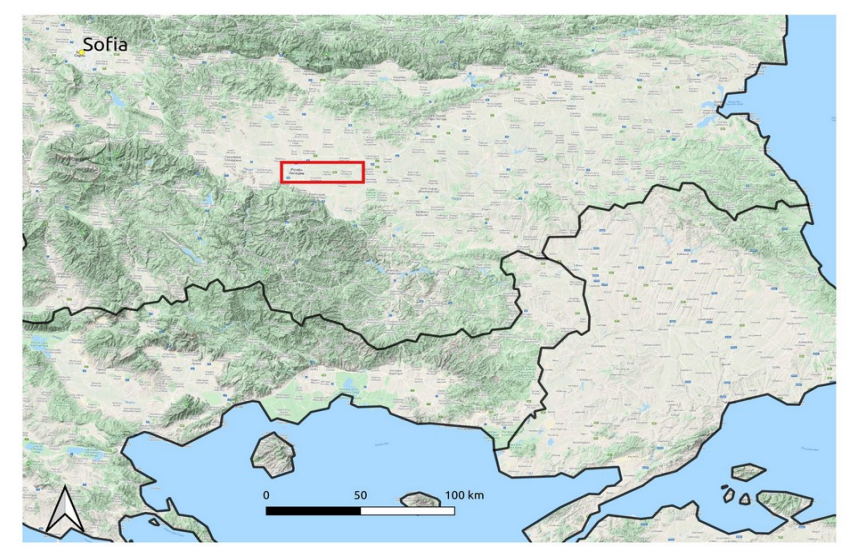

Figure 1: Study area in Plovdiv, Bulgaria. 


\section{DATA}

A Corona image acquired on $17^{\text {th }}$ August 1968 and covering part of Plovdiv was used for the analysis. The KH-4B camera was integrated in this mission (1104-2) to acquire a panchromatic image in the 500-900nm spectral domain and at approximately $2 \mathrm{~m}$ spatial resolution. The Corona image was delivered as a film scan (Figure 2) and consequently with minimal metadata and no ephemeris data. Moreover, the image inherits a low signal-to-noise ratio (SNR) and intense spatial and radiometric distortions are observed; for instance Deroin et al. [17] in a study analyzing Corona KH4A images avoid annotating geographical coordinates due to the presence of important conical distortion. These technical limitations have perhaps deterred scientists to attempt feature extraction but rather use Corona imagery for visual interpretation purposes. Nevertheless, and referring to our study area, the high spatial resolution of the image reveals crisp man-made land cover features.

An image (ID: DS1104-2155DF041) was ordered from the U.S. Geological Survey. Once Corona images are purchased, the data become available in the public domain through the EarthExplorer, a fact which supports the reproducibility of our results.

For matters of comparison, a Landsat- 8 and a Sentinel-2B image acquired in 21 ${ }^{\text {st }}$ August 2019 and 29 ${ }^{\text {th }}$ August 2019 respectively and covering the same territory were employed, as these satellites have proven their added-value in land use and land cover studies (e.g. [18]). The Sentinel2B was processed at level-1C and downloaded from the Copernicus Open Access Hub, while the Landsat-8 image was delivered at Level-1 processing level (land surface reflectance on-

demand) and was retrieved from the EarthExplorer. Images of the same month (i.e. August) were chosen to eliminate differences in seasonal phenology which might affect vegetation land cover characteristics.

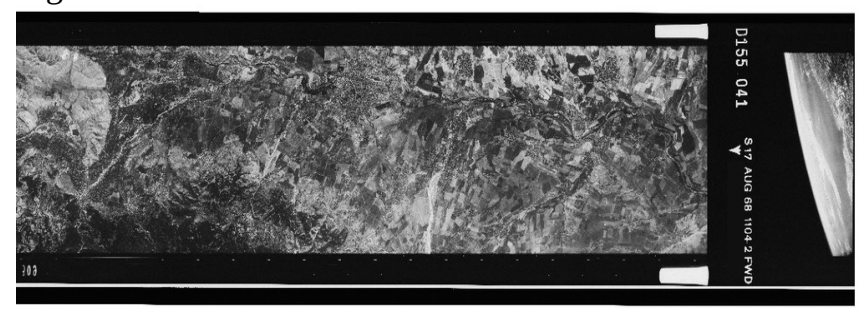

Figure 2: Delivery of a single Corona satellite tile in the form of a scan of the film used to acquire the image.

\section{METHODOLOGY}

The four Corona tiles included in the delivery from EarthExplorer were first stitched together using the Adobe
Photoshop 2020 software. The composed image was then georeferenced with 33 Ground Control Points (GCPs) onto a high resolution base map and projected onto a Universal Transverse Mercator (UTM) coordinate system. We then applied texture analysis as in related studies (e.g. [19]); we made use of the Haralick texture analysis and extracted the following six features: energy, entropy, correlation, inverse difference moment, inertia and Haralick correlation.

Thereafter, the Sentinel-2B and Landast-8 images were subset to the area of interest. For Sentinel-2B, the bands corresponding to a natural color representation were merged (namely bands 2, 3 and 4) and a color composite created. For Landsat-8, bands 6 and 8 were used to extract the Normalized Difference Built-up Index (NDBI) which is a Normalized Difference Spectral Index (NDSI). This index highlights impervious surfaces as it incorporates the shortwave infrared band at the $1600 \mathrm{~nm}$ wavelength and has been used in other studies to extract urban built-up areas (e.g. [20-21]).

All geospatial operations were carried out in QGIS [22] and the Geospatial Data Abstraction Library (GDAL). We present a small subset of the image for matters of visualization clarity, as the settlements size, except the city of Plovdiv, is rather small.

\section{RESULTS AND DISCUSSION}

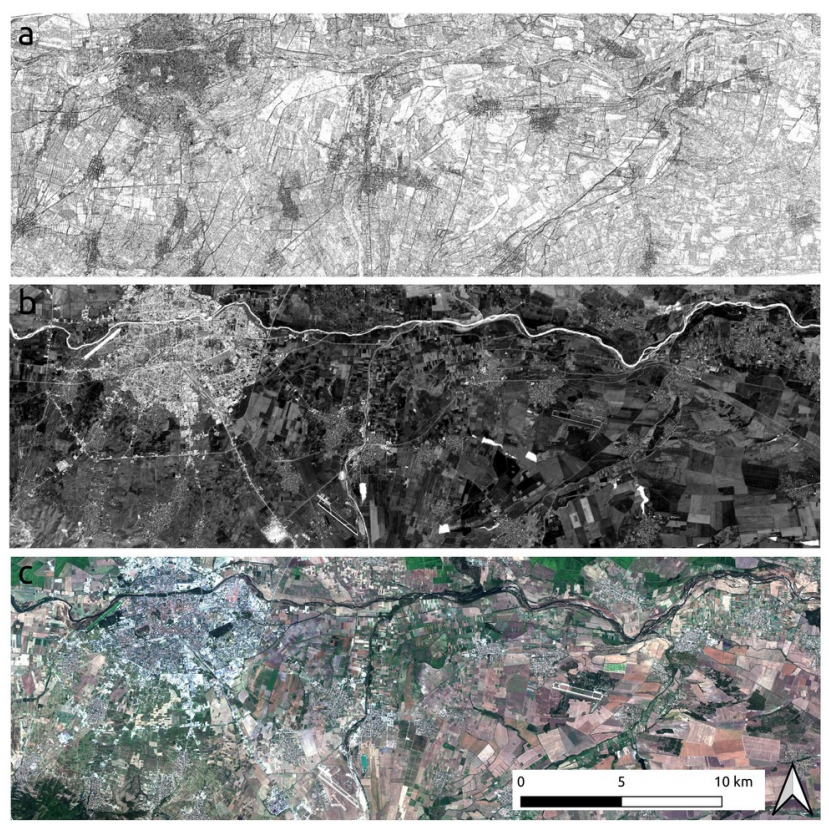

Figure 3: Impervious surface indication (settlements) from texture analysis of a Corona satellite image (a), NDBI of a contemporary Landsat-8 image (b) and natural representation of a contemporary Sentinel-2B image (c) over Plovdiv, Bulgaria. 
All texture features extracted, except the correlation, seem to provide useful information for the settlements and road infrastructure. Moreover, energy and entropy features correlate with certain agricultural fields (results not shown here), information which is probably related to different crop or tree species. The inverse difference moment and inertia texture features highlight settlements from the surrounding areas with a high contrast and are ideal for settlement identification (Figure 3). Settlements appear with lower values (dark clusters) in the inverse different moment layer (Figure 3a) and a visual close-up evaluation for each settlement against the Sentinel-2B image indicates a good fit in the settlements locations. Moreover, the extent of the settlements seems to be representative of the textural layer, which is a sign of the suitability of Corona for feature extraction based on its texture.

The comparison between Corona and the Landsat-8 NDBI index indicates the expansion of the city of Plovdiv (upper left part of the image). While one would expect that the NDBI would reveal the settlements of the study area, this is not the case; only the larger city of Plovdiv is discerned in the visualization of the spectral index while smaller satellite settlements are not mapped out; this perhaps is an indirect consequence of industrial and general activity in the city of Plovdiv comparatively to the smaller settlements. A denser time series between 1968 and 2019 and quantification of the settlement size could probably reveal attributes related to the industrialization under the Bulgarian socialist planned economy, its dissolution with the fall of Communism in Eastern Europe in 1990, and the admission of Bulgaria to the European Union in 2007.

An investigation of the Normalized Difference Vegetation Index (NDVI) for both modern satellite systems did not yield any fruitful results (results not shown here); this is perhaps attributed to the fact of the summer season in this geographic area during the month of August, and consequently vegetation is at its lowest vigor and therefore NDVI tends to have a low standard deviation throughout the image.

Despite the fact that Corona inherits a very high spatial resolution panchromatic image and hence texture analysis is an ideal candidate for image processing in such cases, Corona satellite images have so far been used mainly in the context of visual evaluation, with few notable exceptions such as one from Saleem et al. [23] who used textural analysis as an input in a classification scheme. In this paper we showcase and we reckon that image processing for feature extraction yields tangible results and is worth investigating further.

Corona imagery has been a source of historic information since its declassification giving the opportunity for a comparison of the current land cover status with the cold war era. More importantly, it allows for an establishment of a long historic baseline and an unprecedented satellite image time series availability from 1965 until today; combined with aerial photography and both decommissioned and contemporary satellite images such as those from the Landsat series, a decadal time-scale archive can be built, such as the one presented by Tappan and McGahuey [24] who detected environmental and agricultural conditions from 1965 until 2001 in southern Mali.

In this study, we presented initial findings from the integration of earth observation into the ERC Starting Grant project UrbanOccupationsOETR, (Industrialisation and Urban Growth from the mid-nineteenth century Ottoman Empire to Contemporary Turkey in a Comparative Perspective, 1850-2000, funded by the European Research Council (ERC) under the European Union's Horizon 2020 research and innovation programme (grant agreement No. 679097)) which main focus is on economic history and historical population geography of Turkey, Bulgaria and Greece in the $20^{\text {th }}$ century. We showcase the potential usability of historic satellite Corona images acquired in 1968 in the context of mapping settlements over Plovdiv, Bulgaria. Textural analysis is augmenting the information inherited in this historic satellite data source. Future steps will focus on agricultural mapping as high spatial resolution has a potential in smallholder agriculture [25] and classification schemes based on Object Image Analysis (OBIA) [26].

\section{REFERENCES}

[1] McDonald, R. A. (1995). Opening the Cold War sky to the public- Declassifying satellite reconnaissance imagery. PE \& RSPhotogrammetric Engineering and Remote Sensing, 61(4), 385390.

[2] Ur, J. (2003). CORONA satellite photography and ancient road networks: A northern Mesopotamian case study. Antiquity, 77(295), 102-115.

[3] Goossens, R., De Wulf, A., Bourgeois, J., Gheyle, W., \& Willems, T. (2006). Satellite imagery and archaeology: the example of CORONA in the Altai Mountains. Journal of Archaeological Science, 33(6), 745-755.

[4] Bitelli, G., \& Girelli, V. A. (2009). Metrical use of declassified satellite imagery for an area of archaeological interest in Turkey. Journal of Cultural Heritage, 10, e35-e40.

[5] Casana, J., Cothren, J., \& Kalayci, T. (2012). Swords into ploughshares: Archaeological applications of CORONA satellite imagery in the Near East. Internet Archaeology, 32(2). 
[6] Min, L. (2013). Archaeological landscapes of China and the application of Corona images. In Mapping Archaeological Landscapes from Space (pp. 45-54). Springer, New York, NY.

[7] Comer, D. C., \& Harrower, M. J. eds. (2013). Mapping Archaeological Landscapes from Space. Springer, New York, NY.

[8] McCoy, M. (2018). The race to document archaeological sites ahead of rising sea levels: Recent applications of geospatial technologies in the archaeology of Polynesia. Sustainability, 10(1), 185.

[9] Lasaponara, R., Yang, R., Chen, F., Li, X., \& Masini, N. (2018). Corona Satellite Pictures for Archaeological Studies: A Review and Application to the Lost Forbidden City of the HanWei Dynasties. Surveys in Geophysics, 39(6), 1303-1322.

[10] Nita, M. D., Munteanu, C., Gutman, G., Abrudan, I. V., \& Radeloff, V. C. (2018). Widespread forest cutting in the aftermath of World War II captured by broad-scale historical Corona spy satellite photography. Remote Sensing of Environment, 204, 322-332.

[11] Casana, J., \& Cothren, J. (2008). Stereo analysis, DEM extraction and orthorectification of CORONA satellite imagery: archaeological applications from the Near East. Antiquity, 82(317), 732-749.

[12] Awange, J., \& Kiema, J. (2019). CORONA Historical Declassified Products. In Environmental Geoinformatics (pp. 191199). Springer, Cham.

[13] Mladenov, C. (2002). Population distribution in Bulgaria. Discussion papers, (Special), 20-26.

[14] Rangelova, R. (2003). Bio-demographic change and socioeconomic trends in Bulgaria. Economics \& Human Biology, 1(3), 413-428.

[15] UN Department of Economic and Social Affairs, Population Division. (2019). World Population Prospects 2019 Highlights, United Nations, New York.

[16] Kabadayı, M. E., Gerrits, P., \& Boykov, G. (2020). Bridging the Gap between Pre-census and Census-era Historical Data: Devising a Geo-sampling Model to Analyse Agricultural Production in the Long Run for Southeast Europe, 1840-1897. International Journal of Arts and Humanities Computing: A Journal of Digital Humanities, 14 (1-2), 46-63.

[17] Deroin, J. P., Téreygeol, F., Cruz, P., Guillot, I., \& Méaudre, J. C. (2012). Integrated non-invasive remote-sensing techniques and field survey for the geoarchaeological study of the Sud Lípez mining district, Bolivia. Journal of Geophysics and Engineering, 9(4), S40-S52.

[18] Nuthammachot, N., \& Stratoulias, D. (2019). Fusion of Sentinel-1A and Landsat-8 images for improving land use/land cover classification in Songkla province, Thailand. Applied Ecology and Environmental Research, 17(2), 3123-3135.

[19] Alonso, M. C., Sanz, M. A., \& Malpica, J. A. (2007, November). Classification of high resolution satellite images using texture from the panchromatic band. In International symposium on visual computing (pp. 499-508). Springer, Berlin, Heidelberg.

[20] Alhawiti, R. H., \& Mitsova, D. (2016). Using Landsat-8 data to explore the correlation between urban heat island and urban land uses. IJRET: International Journal of Research in Engineering and Technology, 5(3), 457-466.

[21] Zha, Y., Gao, J., \& Ni, S. (2003). Use of normalized difference built-up index in automatically mapping urban areas from TM imagery. International journal of remote sensing, 24(3), 583-594.

[22] QGIS Development Team (2020). QGIS Geographic Information System. Open Source Geospatial Foundation Project. http://qgis.osgeo.org

[23] Saleem, A., Corner, R., \& Awange, J. (2018). On the possibility of using CORONA and Landsat data for evaluating and mapping long-term LULC: Case study of Iraqi Kurdistan. Applied Geography, 90, 145-154.

[24] Tappan, G., \& McGahuey, M. (2007). Tracking environmental dynamics and agricultural intensification in southern Mali. Agricultural Systems, 94(1), 38-51.

[25] Stratoulias, D., De By, R. A., Zurita-Milla, R., Bijker, W., Tolpekin, V., Schulthess, U., \& Ahmed, Z. U. (2015, January). The potential of very high spatial resolution remote sensing in applications in smallholder agriculture. In 36th Asian Conference on Remote Sensing, ACRS 2015: Fostering Resilient Growth in Asia.

[26] Blaschke, T. (2010). Object based image analysis for remote sensing. ISPRS journal of photogrammetry and remote sensing, 65(1), 2-16. 